JALADRI (Vol. 6.1) (2020)

Jurnal Pendidikan Bahasa dan Sastra Daerah

http://jurnal.upmk.ac.id/index.php/jaladri/

\title{
ASPEK SOSIAL DALAM KUMPULAN CERITA ANAK NGALA \\ JANGKRIK KARYA HOLISOH ME
}

Siti Ainun Mahpulah, Imas, Finza

siti@gmail.com

Departemen Pendidikan Bahasa Sunda

Universitas Pendidikan Indonesia

\section{Info Artikel}

Sejarah Artikel:

Diterima : 10 Januari 2020

Disetujui : 10 April 2020

Dipublikasikan : 25 April 2020

Kata Kunci:

$$
\begin{array}{lr}
\text { Ngala } & \text { Jangkrik, } \\
\text { aspek } & \text { sosial, } \\
\text { aspek } & \text { ekonomi, } \\
\text { aspek pendidikan }
\end{array}
$$

\begin{abstract}
Abstrak
Penelitian ini bertujuan untuk mendeskripsikan aspek sosial yang terdapat dalam kumpulan cerita anak Ngala Jangkrik karya Holisoh ME. Métode yang digunakan yaitu deskriptif kualitatif, dengan langkah-langkah mengumpulkan data, menganalisis dan mendeskripsikan data. Adapun teknik yang digunakan adalah studi pustaka. Sumber data utama adalah kumpulan cerita anak Ngala Jangkrik karya Holisoh ME. Hasil penelitian ditemukan tiga aspek sosial yaitu aspek sosial agama, aspek sosial ekonomi, dan aspek sosial pendidikan. Kumpulan cerita anak Ngala Jangkrik karya Holisoh ME memiliki 9 sub judul cerita, 8 di sub judul di antaranya mengandung aspek sosial agama yang terdiri atas 20 aspek sosial agama. Selain itu dalam 8 sub judul tersebut terdapat tiga aspek kelas sosial, yaitu aspek sosial ekonomi kelas atas, menengah, dan aspek sosial ekonomi kelas rendah dengan jumlah 21 aspek sosial ekonomi. Kemudian aspek sosial pendidikan terdapat dalam 9 sub judul cerita dengan jumlah 16 aspek sosial pendidikan.
\end{abstract}


Key Words:

Ngala Jangkrik,
social aspects,
economi aspects,
education aspects

This research aims to increase public awareness in appreciating literary works in which there are social aspects. This study aims to describe the social aspects contained in the kumpulan cerita anak "Ngala Jangkrik" by Holisoh ME. The method used in this research is descriptive qualitative research, using steps to collect data from the children's story kumpulan cerita anak Ngala Jangkrik, analyzing the data collected, and describing the data. The main data source of this research is the book Ngala Jangkrik by Holisoh ME. The purpose of this study is to examine the conditions, conditions, and results written in the form of reports with literature study techniques. The results of the study found 3 social aspects, namely the social aspect of religion, the social economic aspect, and the social aspect of education. The kumpulan cerita anak Ngala Jangkrik by Holisoh ME has 9 story titles. From the kumpulan cerita anak "Ngala Jangkrik" there are 8 story titles that contain social aspects of religion and have 20 social aspects of religion. In addition, there are three aspects of social class, namely the socioeconomic aspects of the upper class, middle class, and socioeconomic aspects of the lower class contained in 8 story titles with a total of 21 socioeconomic aspects. The last social aspects of education are contained in 9 story titles with a total of 16 social aspects of education. 


\section{PENDAHULUAN}

Sastra merupakan karya seni yang diciptakan menggunakan media bahasa (Isendes, 2010). Karya sastra tercipta karena keinginan pengarang untuk mengungkapkan eksistensinya sebagai seorang manusia yang mempunyai gagasan, ide, dan pesan yang terdapat dalam karyanya, baik terinspirasi dari kehidupan sosial maupun budaya, serta menggunakan bahasa sebagai medianya. Karya sastra dianggap sebagai bentuk ekspresi dari pengarang (Aniswanti \& Wahyuningtyas, 2016). Sastra juga dapat diartikan sebagi sebuah karya kreatif sekelompok masyarakat. Tujuan umum untuk mempelajari sastra adalah agar mampu menikmati, dan memanfaatkan karya sastra untuk mengembangkan kepribadian, memperluas wawasan kehidupan, serta meningkatkan pengetahuan dan kemampuan berbahasa (Prasetiyo, 2017). Selain itu, dikatakan Suherman (2019: 269) bahwa mempelajari dan membaca karya sastra merupakan salah satu kegiatan literasi budaya.

Tulisan ini mengkaji kumpulan cerita anak Ngala Jangkrik karya Holisoh ME dengan pendekatan sosiologi sastra. Novél adalah prosa rekaan yang berbentuk naratif, dengan cerita yang panjang, dan memiliki alur yang bercabang (Parlina, Dkk. 2019),sedangkan sosiologi sastra menurut Theew (dalam Widia 2015) adalah analisis yang berdasarkan aspek-aspek sosial dan otonomi sosial masyarakat di dalam karya.

Teori sosial sastra memiliki cakupan historis yang cukup besar dibandingkan dengan sosiologi sastra. Teori sosial mencakup sosiologi sastra, estetika, resepsi sastra kritik, dan sejarah sastra.

Tujuan sosiologi sastra adalah meningkatkan pemahaman terhadap sastra dalam kaitannya dengan masyarakat, menjelaskan bahwa rekaan tidak berlawanan dengan kenyataan, dalam hal ini karya sastra disusun secara imajinatif, tetapi kerangka imajinatifnya tidak bisa difahami di luar kerangka empirisnya dan karya sastra bukan semata-mata merupakan gejala individual tetapi gejala sosial (Aniswanti \& Wahyuningtyas, 2016).

Aspek sosial menurut anwar (dalam, Sari 2019) membahas tentang kenyataan yang dihubungkan dengan kehidupan sehari- hari, yang dilihat dari keadaan, kejadian, dan proses. Keadaan bersifat statis sedangkan kejadian bersipat dinamis. Karya sastra adalah produk sosial. Sebab di dalam karya sastra membahas bentuk kehidupan masyarakat.

Aspek sosial adalah suatu tindakan untuk menghadapi masalah sosial. Masalah sosial ini timbul akibat tingkah lakunya. Masalah sosial tidaklah sama, karena adanya perbedaan dalam tingkat perkembangan dan kebudayaannya, sifat kependudukannya, dan keadaan lingkungan alam. Oleh karena itu permasalahan yang timbul di masyarakat harus dicegah dengan cara menerapkan moral yang baik sedini mungkin. Ditinjau dari aspek sosial, kumpulan cerita anak Ngala Jangkrik memiliki banyak hal yang dapat dijadikan sebagai bahan moral bagi anak-anak.

\section{METODE PENELITIAN}

Penelitian deskriptif adalah penelitian yang berusaha mendeskripsikan dan menginterpretasikan sesuatu, misalnya kondisi atau hubungan yang ada, pendapat yang berkembang, proses yang sedang berlangsung, akibat atau efek yang terjadi, atau tentang kecenderungan yang tengah berlangsung (Linarwati dkk. 2016). Dalam penelitian ini digunakan metode deskriptif kualitatif, objeknya yaitu karya sastra.

Sumber data yang dipakai dalam penelitian ini yaitu kumpulan cerita anak Ngala Jangkrik karya Holisoh ME. Teknik mengumpulkan data dalam penelitian ini menggunakan teknik studi pustaka, dengan langkah-langkah yaitu mencari sumber data yaitu kumpulan cerita anak Ngala Jangkrik, selanjutnya membaca naskah, mengidentifikasi masalah yaitu menyangkut aspek sosial agama, ekonomi, dan pendidikan, yang terakhir merumuskan masalah.

\section{HASIL DAN PEMBAHASAN}

\section{Aspek Sosial Agama}

Aspek sosial agama adalah salah satu hal yang harus ada dalam sastra anak, tujuannya untuk pendidikan karakter anak. Aspek dasar pendidikan karakter sastra anak adalah iman dan taqwa. Aspek inilah yang disebut oleh Suherman (2018: 110) sebagai pembentuk manusia seutuhnya, yang seimbang lahir dan batinnya. Indikator yang bisa diteliti dalam aspek ini adalah percaya terhadap SWT, menjalankan perintah Allah, sabar, mengamalkan ajaran islam, dan syukur kepada Allah SWT. Selain itu, dalam aspek ini juga terdapat indikator sikap yang 
mencerminkan keagamaan yaitu saling memberi, menuruti petuah orang tua, dan bersikap baik. Aspék sosial agama yang terdapat dalam kumpulan cerita anak Ngala Jangkrik dengan judul cerita yaitu "Budak Baguer", "Bebas, Euy", "Mikat", "Kokojayan",

"Ngala Jangkrik", "Imtihan", "Disunatan", dan

"Hatam". Dengan jumlah 20 aspek sosial

agama.

\section{Cerita pendek "Budak Bageur"}

"Unggal poé tatéh tara élat. Mana tanginas naker hudangna gé, tara kapiheulaan ku adan subuh". (NJ, hl. 7).

Dari kutipan di atas terdapat aspek sosial agama yang termasuk kedalam golongan menjalankan perintah Allah yaitu sholat Subuh. Meskipun tidak dijelaskan bahwa tokoh dalam cerita ini sholat subuh tetapi dengan perilaku tokoh yang bangun sebelum waktu subuh bisa dikatakan bahwa dia selalu menajankan ibadah sholat subuh.

Cerita pendek "Bebas, Euy"

"Téténong dibukaan. Ukur aya beuleum asin tiga waja opat siki, sambel goang dina coét taneuh, jeung seupan kiciwis sapiring. Alhamdullilah sakieu gé aya dahareun. Sanguna mah na boboko metung. Ngan geus tiis da sangu tadi subuh" (NJ,hl. 15).

Dari kutipan di atas terdapat aspek sosial agama yang termasuk kedalam golongan bersyukur kepada Allah SWT. Bisa dilihat dari kata Alhamdulillah yang memiliki arti segala puji bagi Allah, yaitu mensyukuri segala rizki yang telah Allah berikan kepadanya.

"Nya pasti atuh da sok maké spiker!", tembal téh da enya sakola kuring mah mun ngayakeun rapat téh sok nginjeum spiker ti masigit. Malah ari samen gé sepikerna téh anu masihit. Atuh masigit gé mun ngayakeun acara saperti isro mi'roj, hiji Muharom, apan sok nginjeum bangku sakola, da masigit mah leutik teu bisa ngasupekeun jelema loba (NJ,hl. 18).

Kutipan di atas termasuk kedalam golongan saling membantu dalam hal kebaikan. Dalam Islam setiap diwajibkan saling membantu. Selain itu lingkungan kehidupan tokoh pun mengamalkan ajaran Islam dengan cara memperingati isra mi'raj dan satu Muharam.

Cerita pendek "Mikat"

"Yu ah, geus burit. Karunya tuh nu jauh bisi kamagriban di jalan" (NJ,hl. 29).

Kutipan di atas termasuk mengindikasikan menjalankan perintah Allah SWT,yaitu sholat magrib. Disini secara tidak langsung ada kekhawatiran dari tokoh cerita, tertinggal menjalankan sholat berjamaah.

Cerita pendek "Kokojayan"

"Hempek kainyah!” ceuk kuring bari kop nyokot hiji, ngamimitian. Kup-kop kabéh nyarokot. Puhh, puhh, ditariupan da puguh panas kénéh. Geus rada haneut kari diablemkeun. Alaa, mani ni'mat. Karasa uyahna jaba pulen. Memenitan geus béak, kari piringna (NJ,hl. 32)

Kutipan di atas termasuk kedalam aspek sosial agama yaitu saling memberi. Dalam Islam, sikap saling memberi sangat dianjurkan.

Cerita pendek "Ngala Jangkrik"

"Ari kuring mah mun tass ti tajug, sok geuwat saré, sieun kabeurangan jeung sieun nundutan di kelas (NJ,hl. 41).

Kutipan di atas termasuk kedalam golongan menjalankan perintah agama yaitu sholat. Kata tajug mengandung arti tempat sholat sejenis mushola kecil. Dapat dikatakan bahwa tokoh ini menjalankan perintah Allah.

"Ke, atuh sabar, Sujang! Oyéng mairan bari kokoréh kana liang ku rokrak (NJ,hl. 45).

Kutipan di atas termasuk mengindikasikan sikap yang harus dimiliki oleh seorang muslim, yaitu sifat sabar. Islam mengajarkan sikap tenang dantidak terburu-buru, sebab terburu-buru adalah perilaku syetan.

"Euweuh, ku kami dipiceun jeung jangkrikjangkrikna!” cek Ema teugeug. Haté meni ngaranjug ngadéngé jangkrikjeung kandangna dipiceun téh. Hég nyieun kandangna waé ogé aya dua poéna, dihadé- hadé. Awi téh diteukteukan sajeungkal-sajeungkal, dirautan, dihampelas nepi ka lemes kawas mika. Ari ayeuna ku Ema dipiceun? Ku teungteuingeun. Meni hayang gantawang wé nyarékan ka Ema, tapi ras inget kana papagah guru ngaji, 
boroning ngalawan, karék nyarita rada tarik atawa nyentak gé geus doraka ka indung mah. Mana ngageremet téh na haté wé, da sieun doraka (NJ,hl. 47).

Kutipan di atas termasuk ke dalam aspek sosial agama, yaitu hormat terhadap orang tua. Tokoh dalam cerita ini mengamalkan ilmu yang ia dapat dari guru ngajinya. Islam mengajarkan bahwa ibu merupakan orang yang harus dihormati, bahkan surga pun ada di telapak kaki ibu.

Carita pendek “Imtihan'

"Mending dititah ngaji wé uing mah.. sidik nempo Quran, asal hadé lagamna, bener idgom idharna!" (NJ,hl. 48)

Kutipan di atas mengindikasikan aspek sosial agama, yaitu memunut ilmu. Memuntut ilmu merupakan kewajiban yang harus dilakukan sejak dari buaian sampai liang lahat, sejak lahir sampai kematian tiba.

"Ti kaanggangan geus ka témbong hareupeun masigit aya panggung jeung deklit nu dipasang di buruan masigit. Kacipta raména. Seug mun imtihan téh, nu lalajo téh ti suklakna ti siklukna. Daratang kajeung kudu marekel obor. Taun kali tuda imtihan mah. Unggal bulan Mulud diayakeunna gé. Bulan nu kacida bersejarahna keur umat Islam, nyaéta gubragkan Kanjeng Nabi Muhammad ka alam dunya (NJ,hl. 53)

Kutipan di atas termasuk ke dalam aspek sosial agama yaitu mengamalkan ajaran agama Islam berupa memperingati kelahiran Nabi Muhammad, panutan bagi umat Islam.

“Geus apal, Nyai, keur engke pidato? Ceuk téh nonom bari ngarérét ka kuring. Kuring balaham-béléhém. "Insya Alloh, Tétéh"! tembal téh (NJ,hl. 54).

Kutipan di atas termasuk ke dalam aspek sosial agama yaitu percaya terhadap kekuasaan Allah SWT dengan cara meyakini segala sesuatu atas kehendak-Nya.

"Saha nu teu soak, kudu nangtung di panggung sorangan bari pidato. Babacaan wé haté téh, muntang ka Gusti Alloh, sing dibéré katenangan (NJ,hl. 54).

Kutipan di atas termasuk ke dalam aspek sosial agama yaitu percaya kepada Allah SWT, yang selalu memberikan pertolongan kepada hambanya yang membutuhkan.

"Asa nolorang pidato téh, taya nu salah. Sarua jeung nu aya dina kertas paméré Pa Ustad. Alhamdulillah, haté dibéré teger. Dibéré tenang (NJ,hl. 55).

Kutipan di atas termasuk ke dalam aspek sosial agama yaitu bersyukur kepada Allah SWT. Tidak menganggap bahwa apa yang dilakukan atas kemampuan sendiri, melainkan atas kehendak Allah SWT.

Carita pendek "Disunatan"

"Sabada sarolat subuh di tajug, kuring diakeup diabringkeun ka kulah Mang Undi, deuk dikeueum (NJ,hl. 56).

Kutipan di atas termasuk kedalam aspek sosial agama yaitu menjalankan perintah Allah SWT yaitu sholat subuh.

"Da énya, lain bobohongan hayang disunatan téh, salian ti éra sok dipoyokan "Babah", ogé nyaho ti Pa Ustad, yén disunatan téh keur umat Islam mah wajib hukumna!” (NJ,hl. 59)

Kutipan di atas termasuk aspek sosial agama menjalankan kewajiban Islam yaitu "disunat. Dalam Islam jika akan melakukan ibadah sholat harus bersih terlebih dahulu dari hadas besar dan kecil. Dengan cara inilah seorang laki-laki dapat melakukan ibadah sholat dalam keadaan bersih dari hadas.

"Alhamdulillah...!" kadéngé sora paraji. Saréréa nu ngalingkung méh bareng nyebut alhamdulillah (NJ,hl. 59).

Kutipan di atas merupakan aspek sosial agama yaitu memuji Allah. Dalam kutipan tersebut ada kata Alhamdulillah untuk mengahiri suatu pekerjaan.

Cerita pendek "Hatam"

"Ema téh suka ati, pédah kuring ngajina tamat, peuting ieu deuk dihatamkeun. Malah lain kuring wungkul, tapi ogé si Didi, Kamil jeung Yayah nu deuk haratam téh. Sarua saréréa gé di arimahna téh keur narumpeng. Numpeng hayam. Da puguh ngarukut hayam mah, teu kudu meuli (NJ,hl. 64)

Kutipan tersebut termasuk ke dalam aspek sosial agama yaitu mengamalkan ajaran agama 
berupa membaca Al- Quran. Tampak sekali bahwa beberapa tokoh dalam cerita ini sangat erat dalam kehidupan beragama.

"Baé lah engké jaga, mun geus bisa usaha sorangan, deuk mulang tarima ka indung bapa téh. Deuk nyaah. Deuk sagala dicumponan pangabutuhna. Deuk sina cicing moal meunang ka sawah moal meunang ka kebon! Karunya capéeun! (NJ,hl. 69).

Kutipan tersebut mengindikasikan aspek sosial agama yaitu menghormati orang tua. Dalam Islam ada ungkapan "rido Allah ada dalam rido orang tua, dan murka Allah ada dalam murkanya orang tua".

"Saba'da solat berjamaah isya, acara hatam dimimitian. Bubuka mah ku si Odoy ngaji, maca surat Al-Baqoroh opat ayat (Nj,hl. 70).

Kutipan tersebut termasuk ke dalam aspek sosial agama yaitu melakukan perintah Allah SWT berupa melaksanakan sholat isya. Selain itu, dalam kutipan di atas terdapat kata "hatam" yang berarti selesai atau tamat membaca AlQuran. Artinya tokoh dalam cerita ini mengamalkan ajaran Islam.

"Alhamdulillah, incu Nini téh pinter ngajina geuning. Sugan wé jaga jadi kiyai!" (NJ,hl. 71).

Kutipan tersebut mengindikasikan aspek sosial agama yaitu memuji dengan menyebut nama Allah SWT. Islam mengajarkan bahwa jika akan memuji ciptaan Allah SWT, maka terlebih dahulu harus memuji yang menciptakannya. Selain itu kata "kiyai" juga menunjukkan bahwa keluarga tokoh Nini berharap agar tokoh utama dalam cerita ini menjadi seorang ahli agama.

\section{Aspek Sosal Ekonomi}

Aspek sosial ekonomi adalah perubahan yang terjadi pada kehidupan keluarga, masyarakat dalam memenuhi berbagai kebutuhan hidup (Prasetiyo, 2017). Aspek sosial menjadi tolak ukur terhadap kelas sosial atas, menengah dan bawah. Dalam kumpulan cerita anak Ngala Jangkrik terdapat tiga aspek kelas sosial yaitu aspek sosial ekonomi atas, aspek sosial ekonomi menengah dan aspek sosial ekonomi rendah yang terdapat dalam 8 judul cerita yaitu "Budak Baguer", "Bebas,Euy", "Mikat" "Kokojayan", "Ngala Jangkrik", "Disunatan", "Hatam" dan "Lalajo Doger Monyet". Dengan jumlah 21 aspek sosial ekonomi.

\section{Cerita pendek "Budak Bageur"}

"Anis jeung indungna, éstu hirup duaan. Bapana Anis geus lila tilar alatan panyakit TBC tulang, nu teu kungsi kaubaran. Kaharti ku kituna mah, boro-boro keur tatamba, dalah keur dahar gé ukur koréh-koréh cok (NJ,hl. 7).

Kutipan di atas termasuk mengindikasikan aspek sosial ekonomi kelas rendah. Sulit dalam menjalani hidup bahkan sebelum ayahnya meninggal dikarenakan tidak bisa berobat sebab kekurangan biaya. Apalagi hanya hidup berdua, maka untuk mencari makan pun susah.

"Enya katambahan deuih kudu nyumbang PMI lima ratus rupia!' tembal Anis bari jongjon ngaléngkah, neuteup sendal capitna nu geus ipis dampalna (NJ,hl. 10).

Kutipan di atas termasuk kedalam aspek sosial ekonomi kelas rendah. Bisa dilihat dari tokoh cerita yang tidak mampu memenuhi bayaran sekolah. Selain itu, kondisi tokoh cerita memang dikisahkan kekurangan biaya untuk mencukupi kebutuhannya.

“Anis deuk mekel keur jajan?” indungna nanya.

"Moal, pan tadi geus mumuluk! Kumpulkeun wé keur mayar ka sakola!" (NJ,hl. 11)

Kutipan tersebut termasuk kedalam aspek sosial ekonomi kelas rendah. Di sini bisa dilihat bahwa tokoh cerita sulit dalam membayar uang sekolah.

"Keur engke istirahat da bieu mah mumuluk heula jeung dadar endog!" omongna bari seuri.

Anis maléngos. Manéhna mah mumuluk téh saukur jeung sangu sangray, dipurulukan uyah. Paling undak jeung goreng belut meunang ngurek emangna, adi bapana. Kitu gé tara mindeng méréna téh, ukur sakali-kalieun wé keur usum macul" (NJ,hl. 11).

Kutipan di atas termasuk kedalam aspek sosial ekonomi kelas atas dan sosial ekonomi kelas rendah. Terdapat dua tokoh yang muncul dalam kutipan tersebut. Tokoh pertama memiliki kehidupan yang cukup, ditandai dengan pola 
makan yang layak, sedangkan tokoh kedua memiliki kehidupan yang kurang baik, terlihat dari makanan yang seadanya.

"Komo mun gedé duitna hayang meuli sapatu manéhna téh, da pantesna budak sakola mah disapatu kawas Ela, kawas Gustini, kawas Nining. Tapi kuma engke wé ceuk indungna. Saukur cukup meuli sendal capit gé geus nuhun" (NJ,hl. 14).

Kutipan di atas termasuk kedalam aspek sosial ekonomi kelas rendah. Terlihat dari situasi dan kondisi tokoh yang tidak mampu mencukupi kebutuhan sekolahnya.

Cerita pendek "Bebas, Euy"

"Tetenong dibukaan. Ukur aya beuleum asin tiga waja opat siki, sambel goang dina coét taneuh, jeung seupan kiciwis sapiring” (NJ,hl. 15)

Kutipan di atas termasuk kedalam aspek sosial ekonomi kelas menengah. Dapat dilihat dari keadaan tokoh yang masih bisa menikmati makanan seadanya.

"Naha maké nitah ngajual béas?" Ema nanya heran. "Keur bayaran... éra geus dua bulan teu mayar!” tembal téh" (NJ,hl. 16).

Kutipan di atas termasuk aspek sosial ekonomi kelas menengah. Sebab masih mampu membayar bayaran sekolah meski harus menjual beras dulu.

Cerita pendek "Mikat"

"Ngajak mikat ka Pasir Sabeulah! Sugan wé meunang Cangkurileung, heug Kang Abo butuheun. Lumayan keur meuli-meuli buku téh ladangna!" tembal teh bari ngoloyong kaluar (NJ,hl. 23).

Kutipan tersebut termasuk kedalam aspek sosial ekonomi kelas rendah. Tokoh dalam cerita ini terlihat mencari penghasilan untuk mencukupi kebutuhannya dengan cara mencari burung ke hutan.

"Sabot kuring sibeungeut gé, sangu geus panas. Deker baé dahar sangu sangray. Ngeunah najan teu maké bawang teu maké cabé gé" (NJ,hl. 24).

Kutipan di atas termasuk aspek sosial ekonomi kelas rendah, sebab tokoh cerita tidak memiliki kehidupan yang layak, termasuk makanan yang seadanya.
"Golosor, dibikeun ka kuring duit kencring lima ratus pérak. Da mémang tara gedé méréna, ukur mahi keur meuli misro atawa comro dua siki (NJ,hl. 25).

Kutipan di atas termasuk aspek sosial ekonomi kelas rendah, tampak dari keinginan tokoh yang tidak terpenuhi.

"Deuk nyarimpang heula? Ema uing boga gula kawung jeung seupan sampeu!” (Nj,hl.27).

Kutipan di atas termasuk aspek sosial ekonomi kelas menengah. Masih dapat menikmati makanan walaupun sederhana.

Cerita pendek "Kokojayan"

"Buku-buku pangajaran mah teu kudu meuli, da geus disadiakeun di sakola tina duit BOS. Jeung ongkoh ketang teu boga duit keur meulina, da anu baroga duit mah mareuli sorangan, boga sorangan (NJ,hl. 31).

Kutipan di atas termasuk aspek sosial ekonomi kelas rendah. Keadaan tokoh cerita dalam kutipan tersebut tidak mampu mencukupi kebutuhannya untuk sekolah. Oleh sebab itu sumbangan BOS begitu membantu kebutuhan tokoh.

"Enya,, Cép Edi anak Kuwu Désa Sukaasih!" ceuk Cep Edi nikukur. Si Kojin balahambéléhém... sangeuk meureun urusan jeung anak Kuwu mah, sieun dibawa ka Balé Desa ku Hansip (NJ,hl.35).

Kutipan di atas termasuk aspek sosial ekonomi kelas atas. Bisa dilihat dari sikap tokoh yang bangga atas pangkat orang tuanya.

Cerita pendek "Ngala Jangkrik"

"Di jalan guk-gok jeung babaturan nu sarua pada-pada deuk ngarit. Oyéng, Hamim, Diat, jeung Udung (NJ,hl. 40).

Kutipan tersebut termasuk aspek sosial ekonomi kelasmenengah. Dapat dilihat dari cara hidup tokoh cerita dalam memenuhi kebutuhannya. Dengan cara memelihara hewan untuk dijual.

"Da, sok ngadéngékeun warta tina radio yén di daérah anu loba budak atawa kolot anu busung lapar. Asa teu kacipta, kumaha ari nu busung lapar, da di lembur kuring mah tacan pernah aya nu busung lapar (NJ,hl. 41). 
Kutipan di atas termasuk aspek sosial ekonomi kelas menengah. Sebab masih mampu makan dan tidak mengalami kelaparan seperti daerah lain.

Ceria pendek "Disunatan"

"Karérét Bapa ngaluarkeun palastik wadah bako tina saku kamprétna. Kumplit jeung daun kawungna nu geus meunang neukteukan (NJ,hl.57).

Kutipan tersebut termasuk kedalam aspek sosial ekonomi kelas menengah. Bisa dilihat dari kehidupan tokoh yang mampu melakukan keinginannya. Bagi sebagian orang yang memiliki penghasilan, rokok merupakan keinginan. Tetapi bagi yang kurang mampu, jangankan untuk membeli rokok, untuk mencukupi kebutuhan saja sudah sulit.

"Mani geus mayakpak dahareun dina téténong jeung baskom. Na téténong mah aya bakakak, beuleum ketan hideungjeung bodas sagedé-gedé bal bliter, kulub endog hayam aya opatna, kuéh bolu nu luhurna dipapaésan ku bonéka budak sunatan, jeung rupaning kadaharan séjénna. Ari dina baskom mah sangu tumpeng nu buni dikarimbun ku daun cau. Hésé ngabadéna, naon eusina (NJ,hl. 58).

Kutipan tersebut termasuk aspek sosial ekonomi menengah. Bisa dilihat dari mampunya tokoh cerita dalam merayakan acara sunatan meskipun tidak semeriah acara sunatan yang lain.

Cerita pendek "Hatam"

"Tapi kasawang deui, kuring bakal maké baju kamprét anyar, meunang ema mangkukna meuli ti pasar. Kamprét kelir héjo, kopéahna hideung, kopéah buludru. Sarungna mah deuk maké nu urut disunatan wé, eta gé hadé kénéh jarang dipaké (NJ,hl.64).

Kutipan di atas termasuk aspek sosial ekonomi kelas menengah. Tokoh mampu membeli barang-barang meskipun tidak semua keinginan terpenuhi.

"Sarua, Aka. Apan meuncit hayam gé jadi dua jeung nu borontok. Nu jago mah dieusikeun kana tumpeng keur ka tajug, nu borontok mah dikana tumpeng Akakeun!" ceukma daria (NJ,hl. 67).

Kutipan tersebut termasuk kedalam aspek sosial ekonomi kelas menengah. Tokoh mampu menikmati makanan yang layak dan mampu memberikan makanan kepada orang lain meskipun harus mengorbankan peliharaannya.

Cerita pendek "Lalajo Dogér Monyét"

"Ari ilaing deuk ngarit engké mulang sakola?" tanya Akri sabada ngahuleng sabaraha jongjonan (NJ,hl. 73).

Kutipan di atas termasuk kedalam aspek sosial ekonomi kelasmenengah. Bisa dilihat dari cara hidup tokoh cerita dalam memenuhi kebutuhannya, yaitu dengan cara memelihara hewan untuk nantinya dijual.

"Keur engké balikna Eteh, deuk meuli surabi di tungturunan!"

"Heueuh atuh, ké Eteh pangmeulikeun nya? Maké oncom" omongna bari nyodorkeun duit sarébu pérak (NJ,hl. 76).

Kutipan tersebut termasuk kedalam aspek sosial ekonomi kelas menengah, mampu membeli keinginannya meski tidak seberapa.

\section{Aspek Sosial Pendidikan}

Aspek sosial pendidikan sangat penting untuk mengajarkan norma-norma kepada anakanak melalui isi cerita. Buku pun bisa dijadikan bahan untuk pengajaraan moral bagi anak-anak. Sebab anak-anak lebih tertarik terhadap cerita. Titik fokus anak-anak akan tertuju kepada alur cerita. Dengan begitu anak-anak akan lebih memahami maksud yang terdapat di dalam cerita.

Aspek sosial pendidikan memiliki beberapa unsur yaitu rasa hormat terhadap orang tua, saling membantu, menuruti nasihat, berterima kasih, menepati janji, memiliki etika, dan mematuhi aturan yang ada di masyarakat. Penjelasan dan peneladanan aspek-aspek tersebut akan membantu anak mengenali nilai-nilai kebangsaan, sebagaimana dikatakan Suherman (2019: 347; 2020: 1501).

Aspek sosial pendidikan dalam kumpulan cerita Ngala Jangkrik yaitu terdapat pada cerita "Budak Baguer", "Bebas, Euy", "Mikat", "Kokojayan", "Ngala Jangkrik", "Imtihan", "Disunatan", "Hatam" dan "Lalajo Doger Monyet".

Cerita pendek "Budak Baguer"

"Malah lamun ka guru mah, ku indungna Anis sok diembohan hiji atawa dua. Padalah guruguruna mah sok nyarék ulah embah- emboh. 
Tapi meureun hayang tumarima ka nu geus ngatik anakna" (NJ,hl. 7).

Kutipan tersebut mengindikasikan aspek sosial pendidikan yaitu sikap berterima kasih. Berterima kasih adalah salah satu sikap yang harus dimiliki oleh setiap manusia.

"Awéwé mah teu meunang teurab tarik-tarik teuing, ngéwa kurang sopan!” ceuk indungna daria (NJ,hl. 9).

Kutipan di atas termasuk kedalam aspek sosial pendidikan yaitu etika. Etika menjadi salah satu hal yang penting, sebab jika seseorang tidak memiliki etika, maka dapat dipastikan bahwa dia bukan orang yang baik. Kutipan di atas menunjukkan seorang ibu yang menganjurkan etika yang baik kepada anaknya.

"Ayeuna mah hidep kari getolna wé sakola. Kari pinterna. Éra lamun sagala waragad dibébaskeun tapi barodo (NJ,hl. 13).

Kutipan di atas termasuk kedalam aspek sosial pendidikan yaitu berterima kasih. Sikap tersebut termasuk dalam etika yang baik. Dalam kutipan tersebut guru memberi tahu muridnya untuk bertemia kasih atas dana yang telah diberikan dengan cara lebih rajin belajar dan menjadi pintar.

Cerita pendek "Bebas, Euy"

"Nya pasti atuh da sok maké spiker!", tembal téh da enya sakola kuring mah mun ngayakeun rapat téh sok nginjeum spiker ti masigit. Malah ari samen gé sepikerna téh anu masigit. Atuh masigit gé mun ngayakeun acara saperti isro mi'roj, hiji Muharom, apan sok nginjeum bangku sakola, da masigit mah leutik teu bisa ngasupekeun jelema loba (NJ,hl. 18).

Kutipan tersebut termasuk kedalam aspek sosial pendidikan yaitu saling membantu. Hal ini sesuai dengan ajaran agama yang sangat menganjurkan untuk saling tolong-menolong.

"Heueuh nya! Ngan si Nonoy kudu disampeur heula. Tadi téh talatah, lamun deuk ulin kudu disampeur" ceuk Jenab bari ngalieuk ka Mimin (NJ,hl. 18).

Kutipan di atas mengandung aspek sosial pendidikan yaitu sikap menepati janji.

"Enta atuh, lamun deuk caricing di dieu, ulah garandéng! Ke lamun Bapa Kapala nu ngusirna karék nyaho!"ceuk si Emang bari galéos deui. Saréréa nyéréngéh seuri koneng (NJ,hl. 20).

Kutipan tersebut termasuk kedalam aspek sosial pendidikan yaitu mematuhi nasehat. Hal ini sesuai dengan ajaran agama agar mansuia saling nasehat-menasehati dalam kebaikan.

Cerita pendek "Mikat"

"Jeung montong ngala manuk sagala, kéh leuwung téh sepi taya pangeusina” (NJ.hl. 23).

Kutipan di atas termasuk aspek sosial pendidikan yaitu menasehati. Isinya berupa nasehat orang tua kepada anaknya.

"Pék kainyah ngaropi!" ceuk Emana Muтu (NJ,hl. 28).

Cerita pendek "Kokojayan"

"Kudu apik kana buku téh, Sujang! Ulah diacak makéna, da geus kelas genep ayeuna mah. Jeung éntong dihijikeun, kudu misah- misah (NJ,hl. 31).

Kutipan di atas termasuk aspek sosial pendidikan yaitu memberi nasihat agar lebih baik dalam belajar.

"Ngojay di walungan Cilutung!" tembal téh datar

"Kadé ati-ati bisi tilelep, heug keur gedé caina!" ceuk Ema daria (NJ,hl. 33)

Kutipan tersebut mengandung aspek sosial pendidikan yaitu menasehati, agar berhati-hati ketika bermain di sungai.

Cerita pendek "Ngala Jangkrik"

"Injeum atuh ku uing aritna?" omongna daria.

"Yeuh! Na atuh lain diasah heula?" ceuk kuring bari mikeun arit (NJ,hl. 42).

Kutipan tersebut termasuk aspek sosial pendidikan yaitu saling membantu. Dalam sikap saling membantu di atas tercermin jiwa sosial yang tinggi.

“Tah aya kénéh sampeu wedang!” ceuk kuring bari nyodorkeun bungkus sampeu wedang na karésék (NJ,hl. 43).

Kutipan di atas termasuk aspek sosial pendidikan yaitu saling memberi. Hal tersebut terlihat dari sikap tokoh cxerayang membagikan makanannya. 
Cerita pendek "Imtihan"

"Nya ulah! Apan Nyai geus dipercaya ku ustad kudu pidato bubuka," ceuk indungna bangun manglebarkeun (NH,hl. 48).

Kutipan di atas termasuk aspek sosial pendidikan yaitu

memberi motivasi untuk meingkatkan rasa percaya diri dalam melakukan sesuatu.

Cerita pendek "Disunatan"

"Uing deuk dibagi kuéh boluna Jajang?"tanya Samid bari kutap-kétap, neureuyan ciduh.

"Heueuh engké uing geus dikeureut..!" tembal téh bari seuri (NJ,hl. 58).

Kutipan tersebut termasuk aspek sosial pendidikan yaitu saling memberi. Tampak dari sikap tokohcriayang membagi makanannya.

Cerita pendek "Hatam"

"Nya atuh urang do'akeun ku saréréa, si kasep sing jadi budak soléh, anu takwa anu luhung élmu, anu bakti ka indung bapa jeung aya gunana keur agama, nagara, jeung bangsa (NJ,hl. 72).

Kutipan di atas termasuk aspek sosial pendidikan yaitu mendo'akan dan memberi keyakinan terhadap anak untuk menjadi orang yang lebih baik.

Cerita pendek "Lalajo Dogér Monyét"

"Baé lah, teu jajan gé geus soré ieuh! Mending bikeun, yu ti uing lima ratus, ti dinya lima ratus" ceuk kuring daria (Nj,hl. 78).

Kutipan di atas termasuk aspek sosial pendidikan yaitu saling memberi. Sikap perduli terhadap orang lain dan dengan suka rela bahumembahu membantu yang membutuhkan.

\section{KESIMPULAN}

Aspek sosial yang terkandung dalam kumpulan cerita anak Ngala Jangkrik karya Holisoh ME terbagi tiga aspek yaitu aspek sosial agama, aspek sosial ekonomi, dan aspek sosial pendidikan.

Kumpulan cerita anak Ngala Jangkrik memiliki 9 judul cerita yaitu "Budak Baguer", "Bebas, Euy", "Mikat", "Kokojayan", "Ngala Jangkrik", "Imtihan", "Disunatan", "Hatam" dan "Lalajo Doger Monyet".
Dari 9 judul cerita, 8 di antaranya mengandung aspek sosial agama, yaitu terdapat dalam cerita "Budak Baguer", "Bebas, Euy", "Mikat", "Kokojayan", "Ngala Jangkrik", "Imtihan", "Disunatan", dan "Hatam", dengan jumlah 20 aspek sosial agama.

Apek sosial ekonomi dikelompokkan menjadi tiga aspek kelas sosial yaitu, aspek sosial ekonomi kelas atas, menengah, dan aspek sosial ekonomi kelas rendah. Terdapat 8 judul cerita yang mengandung aspek sosial ekonomi yaitu "Budak baguer", "Bebas, Euy", "Mikat", "Kokojayan", "Ngala Jangkrik", "Disunatan", "Hatam" dan "Lalajo Doger Monyet", dengan jumlah 21 aspek sosial ekonomi.

Adapun aspek sosial pendidikan memiliki beberapa unsur, yaitu rasa hormat kepada orang tua, saling membantu, menuruti nasihat, berterima kasih, menepati janji, memiliki etika, dan mematuhi aturan yang ada di masyarakat. Unsur-unsur tersebut terdapat dalam 9 judul cerita yaitu "Budak Bageur", "Bebas, Euy", "Mikat", "Kokojayan", "Ngala Jangkrik", "Imtihan", "Disunatan", "Hatam" dan "Lalajo Doger Monyet", dengan jumlah 16 aspek sosial pendidikan.

\section{REFERENSI}

Anistwanti. Wahyuningtyas. 2016. Aspek Sosial dalam Kumpulan cerita anak Partikel Karya Dewi Lestari: Tinjauan Sosiologi Sastra. Caraka, 3(1). 2016.

Isnendes. Rettu. 2010. Teori Sastra. Bandung: JPBD DPBS UPI.

Linarwati, Mega, Dkk. 2016. Studi Deskriptif Pelatihan dan Pengembangan

Sumberdaya

Manusia Serta Penggunaan Metode Behavioral Event Interview dalam Merekrut Karyawan Baru di Bank Mega Cabang Kudus. Jurnal Of Management, 2(2).

Holisoh, ME. 2018. Ngala Jangkrik. Bandung: Kiblat Buku Utama.

Parlina, Dkk. 2019. Novél Carita Si Dirun Karya Samsoedi Pikeun Bahan Pangajaran Maca di SMP. Dangiang Sunda, 7(3).

Prasetiyo, D. 2017. Analisis Aspek Sosiologi Sastra dalam Kumpulan cerita anak 
Kidung Cinta Buat Pa Guru Karya Mira. Jurnal Sekolah, 2(1).

Sari, K. 2019. Aspek Sosial dina Kumpulan Carita Budak Ulin Di Monumén Karya Tétty Hodijah. Dangiang Sunda, 7(3).

Suherman, Agus. 2018. Jabar Masagi:

Penguatan Karakter Bagi Generasi

Milenial Berbasis Kearifan Lokal.

Lokabasa, 9(2), 107.

Suherman, A. (2019). Literacy Tradition of Sundanese Society-Indonesia.

International Journal for Innovation

Education and Research, 7(3), 262-271.

https://doi.org/10.31686/ijier.Vol7.Iss3.13 77.

Suherman, A., \& Nugraha, H. S. (2019, March).

Culture and Citizenship Literacy in

Sundanese Children's Literature. In Second

Conference on Language, Literature,

Education, and Culture (ICOLLITE 2018).

Atlantis Press.

Suherman, Agus \& Suharno. 2020. The Nationalism Values in Pupuh Lyrics for Elementary School Students. Proceedings The 2nd International Conference on Elementary Education (ICEE) (hlm. 14961506). Bandung: UPI.

Widia, R. Widowati. 2015. Protea Sosial dalam Kumpulan Cerita Pendek Mati Baikbaik, Kawan KaryaMartin Aleida : Pendekatan Sosiologi Sastra. Carak 